A second simple truth is that the quality of intelligence seems now to be good enough to allow governments to count each others' launching sites without actually paying visits to them. Satellites have no doubt played a part in this, although it may be less than some enthusiasts have liked to think. In practice, however, this means that it would be feasible to think of imposing an agreed limit on the numbers of strategic ground-based missiles on each side. The ideal would be the simplest agreement-the limitation of missiles to, say, 200 on each side-enough for a retaliatory blow of great destructiveness but not enough to make a first strike seem tempting.

On the face of things, this is the best agreement that SALT could offer. Public declarations not to work towards the development of anti-ballistic missiles will be illusory-far better simply to require that each side should decide whether to put its efforts into offensive weapons or the equally destabilizing defensive rockets. There remains, however, one obvious and hopeful avenue-the extension of the test-ban to weapons tested underground. In the past few months it has become clear that the remote detection of underground explosions is more than ever feasible. In the long run, this is also the only way in which it will be possible to impede the development of advanced weapons technology. The signature of the non-proliferation treaty three weeks ago, and the willingness of the United States Government to extend its renunciation of biological weapons to include biologically derived toxins, is a sign that things are moving in a cheerful direction. Everybody will be hoping that recent bellicosity about strategic weapons is only a preliminary to hard bargaining at Vienna.

\section{Yeurs Ago}

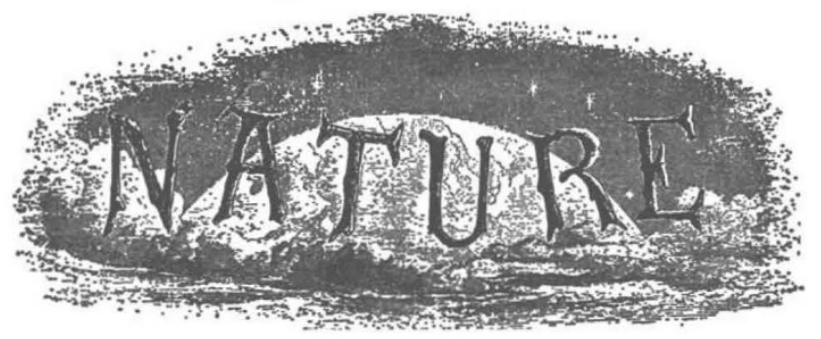

It is stated by the Athencum that a new idea has been broached in a recent lecture by Mr. Bloxam, the lecturer on chemistry to the department of artillery studies. He suggests that the committee on explosives, abandoning gun cotton, should collect the germs of small-pox and similar malignant diseases, in cotton or other dust-collecting substances, and load shells with them. We should then hear of an enemy dislodged from his position by a volley of typhus, or a few rounds of Asiatic cholera. We shall expect to receive the particulars of a new "Sale of Poisons" Act, imposing the strictest regulations on the sale by chemists of packets of "cholera germs" or "small-pox seed." Probably none will be allowed to be sold without bearing the stamp of the Royal Institution, cerlifying that they have been examined by the microscope and are warranted to be the genuine article.

From Nature, 1, 562, March 31, 1870.

\section{OLD WORLD}

\section{LIBEL Science in Court}

A LIBEL action which has serious implications for the scientific community will be brought before the courts sometime next year. Mr Stanley Lithgow DrummondJackson, a dental surgeon, is suing the British Medical Association and the authors of a paper published in the association's journal, the British Medical Journal, because he claims that the paper is defamatory of him in the conduct of his profession. A Court of Appeal has already decided, by two votes to one, that the paper is capable of bearing a meaning likely to be damaging to the dental surgeon, and the stage is now set for what could be a long battle in the High Court.

There is more at stake in this action than the damages being claimed by $\mathrm{Mr}$ Drummond-Jackson, as was recently pointed out by $J$. R. Lewis and his colleagues (Nature, 225, 1081; 1970). The case could change not only the way that scientific papers are written, but it may also deter some journals from publishing criticisms of techniques involving commercial or professional interests. The basis of Mr Drummond-Jackson's claim seems to be that the paper was critical of a technique for dental anaesthesia which was introduced, recommended and used by him, and is, therefore, closely associated with his name. The paper, which was written by Professor J. S. Robinson, Dr C. C. Wise, Dr M. J. Heath and Dr P. J. Tomlin, of the University of Birmingham, also referred to $\mathrm{Mr}$ Drummond-Jackson by name when citing his published papers. Such practices are, of course, common in scientific literature, and Lord Denning, Master of the Rolls, clearly saw the effect that such an action could have on the scientific community. He was reported as saying at the Court of Appeal that "it would be a sorry day if scientists were to be deterred from publishing their findings for fear of libel actions. So long as they refrained from personal attacks, they should be free to criticize the systems and techniques of others. Were it otherwise, no scientific journal would be safe" (The Times, February 14, 1970).

Lord Denning also said that Mr Drummond-Jackson has chosen the course of action which suits him best. The defendants must now prove the correctness of all their tests and experiments, and justify their conclusions to the jury. "To place such a burden on the defendants", he said, "should not be permitted." But the other two Appeals Court judges thought otherwise. Sir Gordon Willmer, for example, said that he could see no danger to scientific communication in dismissing the appeal, and for him the essential feature of the case seems to be that Mr Drummond-Jackson is a practising dental surgeon whose professional reputation is at stake.

The usual way of attacking the views expressed in a scientific paper is to publish another paper stating the opposing case. Such paper discussions are, of course, common among members of the scientific community, but the weapon of a libel action does not seem to have been used before to settle a scientific dispute. There are no exactly comparable legal precedents and this action may be seen by some scientists as a test case, the outcome of which could determine whether they bring similar actions in respect of papers already published. 